How to cite this article:

Mohamad Nasri, N., Halim, L., \& Abd Talib, M. A. (2020). Self-directed learning curriculum: Students' perspectives of university learning experiences. Malaysian Journal of Learning and Instruction, 17(2), 227-251. https:// doi.org/10.32890/mjli2020.17.2.8

\title{
SELF-DIRECTED LEARNING CURRICULUM: STUDENTS' PERSPECTIVES OF UNIVERSITY LEARNING EXPERIENCES
}

\author{
${ }^{1}$ Nurfaradilla Mohamad Nasri, Lilia Halim \& \\ Mohamad Asyraf Abd Talib \\ Faculty of Education, Universiti Kebangsaan Malaysia, \\ Bangi, Selangor, Malaysia
}

${ }_{1}$ Corresponding author: nurfaradilla@ukm.edu.my

Received: 20/3/2020 Revised: 11/5/2020 Accepted: 14/7/2020 Published: 31/7/2020

\begin{abstract}
Purpose - Self-directed learning (SDL) requires students to explore and decide their own learning objectives and strategies, and incorporate the various learning opportunities and resources throughout their learning process. This study investigates the university students' perspectives on university learning experiences and aims to highlight the extent of the university's support ecosystem to determine the effectiveness of SDL implementation.
\end{abstract}

Methodology - Twenty Malaysian public university students were interviewed to obtain their views on SDL, and subsequently, their SDL experiences were further examined. A constructivist grounded theory approach was employed as the methodological and analytical framework for this study. A 'backward-and-forward' approach was applied to analyse the interview data.

Findings - The findings suggested that a large number of university curriculum could potentially inhibit SDL. However, most university students acknowledged that SDL could support their lifelong learning 
journey, and prepare them to be skilful workers. Moreover, most students suggested that the SDL should be implemented as a type of learning where freedom in learning becomes a priority, rather than educator-designed learning strategies.

Significance - The mastery of SDL skills is important to ensure that the students are competent when facing real world challenges. Hence, this study supports the effective implementation of SDL, where both students and educators should acknowledge their roles as equal learning partners.

Keywords: Self-directed Learning, empowerment, freedom, learner autonomy, learner control, students' learning experiences.

\section{INTRODUCTION}

Based on the adoption of a learner-oriented curriculum, university education is geared to promote self-directed learning (SDL) (Guglielmino, 2013). Students are given the freedom to design their own learning practises. However, the freedom in learning causes students to bear greater responsibility and accountability. In addition to attending conventional lectures and classes, students are expected to conduct significant amount of independent study and research. Within this learning context, students who are able to self-direct their own learning would stand to benefit in the universities.

SDL became popular among the $21^{\text {st }}$ century educationalists, and is considered an essential skill for the students' future when facing the competitive labour market (Tekkol \& Demirel, 2018). Therefore, it is necessary to integrate SDL as one of the main components into university curriculums (Douglass \& Morris, 2014; Guglielmino, 2013; Kidane, Roebertsen \& van der Vleuten, 2020). However, there has been growing tensions on addressing SDL as a personal learning endeavour that reflected the learners' psychology or assisted learning activity by the educator who focuses primarily on educators' pedagogical approaches (Guglielmino, 2013). To leverage the full potential of SDL, this study aims to explore the relationship between the two key dimensions of SDL: the psychological dimension and pedagogical dimension.

Although the notion of SDL has been gaining popularity in the context of higher education, there is a lack of initiative to explore 
students' experiences on SDL, particularly in the formal setting (Douglass \& Morris, 2014; Guglielmino, 2013). As a result, education institutions, specifically the educators, are left with no clear guidelines on how to effectively implement SDL to ensure meaningful learning experiences. Failure to systematically address this issue will place Malaysia in a difficult situation due to the lack of skilful and competitive labour force (Morrison \& Navarro, 2014).

Nevertheless, students are poised to greatly benefit from the increased attention to promote effective SDL approaches in education institutions. The main research question in this study is: How do university students in Malaysia conceptualise SDL? In order to gain deeper insights and provide a clearer explanation for this research question, this study investigates the extent of university students in Malaysia that perceive themselves as self-directed learners, and further examine their SDL learning experiences.

\section{LITERATURE REVIEW}

\section{Self-Directed Learning (SDL)}

The Malaysian government, through its various educational policies such as the Malaysia's New Economic Policy and the National Policy on Science, Technology and Innovation (NPSTI), has clearly expressed its aspiration and desire to transform Malaysia from a production-based nation into a knowledge-based economy (Sirat, Ahmad \& Azman, 2012). However, achieving this aspiration requires skilful manpower. Thus, Malaysian universities are responsible to produce knowledgeable, highly motivated and self-directed graduates that could tackle the increasing demand for economic growth. Various contemporary learning approaches have been applied and integrated in universities. One of the many learning approaches that have received growing attention from many educators is SDL.

While SDL has long been recognized as a powerful educational approach that could assist students' future learning, the students' experiences from the ongoing SDL curriculum in many education institutions remain unexplored (Kidane, Roebertsen \& van der Vleuten, 2020; Levett-Jones, 2005; Yeoh, Cazan \& Ierardi, 2017). In order to gain a comprehensive understanding of the outcomes from 
the implementation of SDL, Candy (1991) took into consideration various cognitive, behavioural, social and psychological constructs. Based on the study, it was suggested that the psychological and pedagogical dimensions of SDL should be the key components when investigating students' perceptions and experiences of SDL, particularly in formal learning settings.

\section{Psychological Dimensions of SDL}

The psychological dimensions of SDL are closely associated with individual attributes. Moreover, the self-determination theory developed by Deci and Ryan (2012) has been suggested by many researchers as one of the most suited theory that have successfully addressed the essential issues of SDL such as autonomy, freedom, choice and decision-making.

Self-determination theory postulates that highly self-driven and intrinsically motivated individuals value the freedom to choose and design their own learning. Furthermore, motivated individuals tend to take control of their learning by becoming actively involved in the decision-making process. This is attributed to a fully functioning self-directed learner. As supported by Deci and Ryan (2012) on the role of motivation in SDL, Pink (2011), Douglass and Morris (2014) and Froiland and Worrell (2016) further asserted that intrinsically motivated learners usually achieve higher academic results compared to others. In addition to this, Flint and Johnson (2011) highlighted the essential principle of self-determination theory. The theory suggests that extrinsically motivated learners are initially motivated by various external rewards. However, with the proper strategies, these learners are willing to direct their own learning.

To explore the psychological dimension of SDL, Carré, Moisan and Poisson (2010) suggested that it is important and helpful to review the self-regulated learning (SRL) concept which focuses on the learners' actual learning behaviour once the decision to learn has been made. The term SRL is used interchangeably with other terms in literature, and hence, has created confusion regarding the concepts of SDL. However, the concepts of SRL is fundamental to this study as it will foster a better understanding of SDL from the students' perspectives. To understand the relationship between SDL and SRL, it is important to review the investigations conducted for both SDL and SLR terminologies by Jossberger, Brand-Gruwel, Boshuizen and Wiel's (2010), and Cosnefroy and Carré's (2014). Jossberger et 
al. (2010) and Cosnefroy and Carré (2014) had suggested that SDL was primarily implemented to adult learners who could control and decide their own learning. Furthermore, the study investigated the effective learning strategies that incorporated SRL methodologies within a constrained academic-based system.

Based on the studies conducted by Cosnefroy and Carré's (2014) and Jossberger et al.'s (2010), the significant difference between the concepts of SDL and SRL lies in the control and ownership of learning. In SDL, learners take full control of their whole learning trajectory, and determines the learning goals, strategies, resources and evaluation process. On the other hand, in SRL, self-regulated learners are controlled externally by educators, and infers that the self-regulated learners' control is only limited to the learning activity (Geng, Law \& Niu, 2019; Tekkol \& Demirel, 2018). The findings of this study are in line with the concept of learners' control and ownership of learning, whereby all research participants for this study agreed that, in the context of SDL, learners should take full responsibility and total control over their learning activities.

In relation to this study, the findings on learner's control by Loyens, Magda and Rikers' (2008, p. 418) was noted. According to Loyens et al. (2008), self-regulated learners' control and ownership of their learning are restricted only to the proximal learning goals, while in SDL, learners can decide on their larger distal goals. Additionally, Jossberger et al. (2010) provided a simpler way to understand SDL and SRL by using the micro- and macro-level concepts. The study suggested that SRL, which concerns the micro level, focuses on the task level or learning activity, while SDL places emphasis on the macro level that moves beyond the task level by highlighting the learning trajectory. The findings from Loyens et al.'s (2008) and Jossberger et al.'s (2010) on the level at which SDL and SRL takes place had implied varying degrees of learner control that proved to be helpful in understanding the link between both concepts. For instance, self-directed learners possess greater control of their own learning, compared to self-regulated learners who are bound by certain restrictions within their learning activity that were imposed by an external person. Loyens et al. (2008) and Jossberger et al. (2010) further concluded that SDL included SRL, however SRL does not necessarily include SDL. This finding have not only led researchers to challenge the current views on the relationship between SDL and SRL, but have alerted many researchers to use the terms with caution. 
In order to outline the relationship between SDL and SRL, it is acceptable and reasonable to suggest that SDL includes SRL. Therefore, to be a capable self-directed learner, the learner should be able to self-regulate his or her own learning. It is important to note that SRL alone, which focuses on learning activity, will not produce high levels of performance. Conversely, learners should be able to plan their own learning trajectories that involve self-directed processes to achieve their full potential. The discussion on the relationship between SDL and SRL has highlighted key features of SDL, for which this study aims to examine.

\section{Pedagogical Dimensions of SDL}

Although self-directed learners may choose to learn by themselves, many researchers strongly believe that for effective self-direction, self-directed learners should interact and value the contributions of others in their learning (e.g. Gibbons, 2002, Griffiths, 2008; Merriam et al., 2007; Sze-Yeng \& Raja Hussain, 2013; Kovalenko \& Smirnova, 2015; Woezik, Reuzel \& Koksma, 2019; Thornton, 2010; Karlsson, Kjisik \& Nordlund, 2007). In these circumstances, the role of educators are vital, particularly when assisting and guiding these learners to be successful self-directed learners. Moreover, with regards to the notion of educators as mediators and facilitators during the learning process, Brockett and Hiemstra (1991) highlighted four pertinent pedagogical strategies that could potentially promote SDL: (a) using various teaching and learning resources; (b) encouraging students' active engagement; (c) maximising peer learning activities for meaningful interaction; and (d) fostering supportive atmosphere and constructive interaction.

The shift from directive to facilitative teaching approaches indicate that learners, rather than educators, are the main component that promotes the learning and teaching process. This shift requires educators to acknowledge students as active agents of learning by empowering them to take control and be responsible for their learning (e.g. Trigwell \& Prosser, 1991; Herman, 2012; Flint \& Johnson, 2011; Douglass \& Morris, 2014; Tekkol \& Demirel, 2018). Thus, it is reasonable to insinuate that active learning is essential to promote SDL.

Furthermore, Grow (1991) proposed that to design effective SDL pedagogical processes, strategies should be devised meticulously based on the students' readiness and their level of self-direction. 
Although the findings by Grow (1991) are considered old, they have continued to be a key source of reference for many researchers that investigated learning and teaching methodologies (e.g. Weimer, 2002; Song \& Hill, 2007; Merriam et al., 2007; Tekkol \& Demirel, 2018; Kidane, Roebertsen \& van der Vleuten, 2020).

Grow (1991) proposed the Staged Self-Directed Learning (SSDL) model and emphasised the need for educators to ensure a compatible match between predetermined learning and teaching activities, with students' readiness and ability in self-direction. The two fundamental principles of Grow's (1991) model are: (a) pedagogical approach should be designed to be intellectually challenging, but within the student's zone of proximal development, and (b) the educator is held responsible for matching the pedagogical approach with the student's level of self-direction, while preparing them to transition towards a higher degree of self-direction. In relation to the SSDL model, Grow (1991) made three important assumptions: (a) being a dependent learner is not an offence, but it may limit the learner's full potential; (b) the ability to self-direct is situational, where one may be self-directed in one area but dependent in another area; and (c) self-directed learners usually work collaboratively with other learners and experts.

According to the fundamental concept of the SSDL model by Grow (1991), an educator is responsible to foster the development of SDL skills among their students by guiding them from their preferred learning styles toward better self-direction learning approaches (Grow, 1991). Grow (1991) further concluded that challenging learning context and discouragement from the educators may potentially inhibit SDL.

Recognizing that the SSDL model was an excellent framework for educators to use when promoting SDL, Grow (1994) asserted that educators should begin the instructional process of matching instructional strategies to the learners' learning styles. However, it is argued that this approach was questionable, especially if educators adopted a mismatched instructional style that would impede the advancement of self-direction (Abu-Asba, Azman \& Mustaffa, 2014; Akbarzadeh \& Fatemipour, 2014). Nonetheless, Grow's (1994) SSDL model offers a comprehensive view on the role of educators in facilitating learners' self-direction. Table 1 presents Grow's (1991) SSDL model. 
Table 1

The Staged Self-Directed Learning (SSDL) Model (Source: Grow, 1991)

\begin{tabular}{|c|c|c|c|}
\hline & Students & Teachers & Examples \\
\hline Stage 1 & Dependent & Authority, Coach & $\begin{array}{l}\text { Coaching with immediate } \\
\text { feedback. Drill. }\end{array}$ \\
\hline Stage 2 & Interested & Motivator, Guide & $\begin{array}{l}\text { Inspiring lecture plus } \\
\text { discussion. Goal setting } \\
\text { and learning strategies. }\end{array}$ \\
\hline Stage 3 & Involved & Facilitator & $\begin{array}{l}\text { Discussion facilitated by } \\
\text { teacher who participates } \\
\text { as equal. Seminar. Group } \\
\text { projects }\end{array}$ \\
\hline Stage 4 & Self-directed & Consultant, Delegator & $\begin{array}{l}\text { Internship. Dissertation. } \\
\text { Individual work on self- } \\
\text { directed study group }\end{array}$ \\
\hline
\end{tabular}

Based on the literature reviewed, both students and educators play a significant role to the development of learners' skills for selfdirection. However, there has been a limited number of research conducted that investigates the learners' perceptions on the practices of SDL. Hence, this study investigates the perceptions of Malaysian university students' conceptualisations and experiences on SDL.

\section{METHODOLOGY}

The main purpose of this study is to investigate university students' perceptions and experiences on the SDL curriculum. The main research question in this study is: How do university students in Malaysia conceptualise SDL? In order to highlight the extent of the university's support ecosystem to determine the effectiveness of SDL implementation from the students' point of view, a qualitative approach was employed for this study.

\section{Sampling Approach}

Snowball sampling was chosen for this study as it is convenient, efficient and economical (Cohen \& Arieli, 2011; Gentles, Charles, Ploeg \& McKibbon, 2015). Despite these advantages, snowball sampling has the potential for biasness (Sadler et al., 2010; Gentles 
et al., 2015) as it may only include individuals that are connected to this interrelated circle, while excluding others. Nonetheless, this issue does not pose any problems for this study as it is not aimed at making any claims and generalisation to the wider population of university students. A total of 20 research participants consisting of university students took part in this study. The number of participants chosen were adequate to provide sufficient data on the students' perceptions and experiences of SDL curriculum. Two general selection criteria were maintained when selecting the research participants: (a) third year public university students, and (b) studying at an education faculty.

\section{Research Participants' Profile}

Using the snowball sampling approach, a total of 20 third year university students, who volunteered to be research participants from the faculty of education from four different public universities $(n=8$ males and $n=12$ females) were interviewed through a semi-structured interview process to examine their perceptions and experiences on SDL. Out of the 20 research participants, nine students were from the TESL programme, eight students were from the Special Education programme, and three students were from the Sports and Recreation programme. Table 2 outlines each research participant's pseudonym (with label), gender and study programme.

Table 2

Research Participant's Pseudonym, Gender, and Study Programme

\begin{tabular}{llll}
\hline \multicolumn{1}{c}{ Name } & \multicolumn{1}{c}{ Label } & \multicolumn{1}{c}{ Gender } & \multicolumn{1}{c}{ Study programme } \\
\hline 1. Aleesa & RPA & F & TESL \\
2. Aqeela & RPB & F & Special Education \\
3. Ariffin & RPC & M & TESL \\
4. Azida & RPD & F & Sports and Recreation \\
5. Damia & RPD & F & Special Education \\
6. Fahri & RPE & M & TESL \\
7. Farahin & RPF & F & TESL \\
8. Fattah & RPG & M & TESL \\
9. Haziq & RPH & M & TESL \\
\hline
\end{tabular}




\begin{tabular}{llll}
\hline \multicolumn{1}{c}{ Name } & \multicolumn{1}{c}{ Label } & Gender & \multicolumn{1}{c}{ Study programme } \\
\hline 10. Intan & RPI & F & Special Education \\
11. Iskandar & RPJ & M & Special Education \\
12. Jamal & RPK & M & Special Education \\
13. Kamarul & RPL & M & Special Education \\
14. Liana & RPM & F & TESL \\
15. Salina & RPN & F & Special Education \\
16. Sharifah & RPO & F & Special Education \\
17. Sharina & RPP & F & TESL \\
18. Sofea & RPQ & F & Sports and Recreation \\
19. Wafi & RPR & M & Sports and Recreation \\
20. Zaleha & RPS & F & TESL \\
\hline
\end{tabular}

\section{Data Collection Procedure}

To answer the research question, the interview format was chosen to gather data as the research participants would have the opportunity, space and flexibility to express their views without the constraints of predetermined questionnaires (Doody \& Noonan, 2013; Deterding $\&$ Water, 2018). Interview schedule serves as one of the fundamental feature of a semi-structured interview. Moreover, this study employed an active rather than a standard interview schedule, where the interviewer was required to actively engage and build rapport with the research participants (Holstein \& Gubrium, 2008; Romero, Kwan \& Suchman, 2019).

As this study investigates university students' conceptualisations and experiences of SDL, it was important to ensure that the interview questions would successfully explore and answer the research question. Based on the suggestions by Pathak and Intratat's (2012) on the general interview topics to guide interview sessions, five interview topics were developed. The interview topics are as follows:

a) Demographic information, including gender and study programme - demographic information from the research participants were gathered that would allow researchers to understand the research participants' background. This would aid researchers during the data analysis stages of the research to comprehend the reason on why the research participants might hold particular views or opinions; 
b) Students' conceptualisations of learning - a series of questions were carefully designed to allow researchers to explore the research participants' conceptualisations of learning and their methods.

c) Students' conceptualisations and understandings of SDL questions were devised to allow researchers to gain insights into each research participant's perceptions of SDL, and to understand the ways they understood and defined SDL. This would assist researchers in determining the extent to which they viewed learning and SDL; either similar, synonymous or different;

d) Students'perceptions of themselvesas learnersand self-directed learners - the questions on the students' conceptualisations of themselves as learners and self-directed learners were developed to investigate the research participants' perceptions and understanding of the concepts of 'learner' and 'educator'. In addition, this interview topic is considered to be a useful method to highlight the views of the research participants on themselves and the educators in the educational environment; and

e) The opportunities they had to practise SDL - the set of questions were devised to allow researchers to explore in detail the research participants' experiences of learning, assessment and feedback practices.

The interview schedule was piloted to determine the length of the interview sessions, to test the suitability of the interview topics devised, and gain valuable feedback from the pilot research participants on the clarity of the interview questions. Two university students, who volunteered to participate in the pilot interview schedule, are not involved in the main research study. The pilot research participants commented favourably on the interview questions, and suggested that it helped them reflect and share their understanding on the topic. Hence, the interview questions were used for this study as they were precise and easy to understand.

\section{Process of Organizing the Interviews}

To gather the basic contact information for the potential research participants such as emails and phone numbers, the universities' graduate centres were contacted. The potential university students were then contacted, via email, to obtain their approval to participate in this study. Upon obtaining their agreement to voluntarily participate in the current study, an appointment for the interview was 
arranged with the relevant date, time and interview location. Most of the interview sessions lasted for about one hour, and were recorded using recording devices. This enabled researchers to repeatedly listen to the recorded interview sessions when needed.

\section{Data Analysis Approach}

A 'backward-and-forward' hybrid approach of thematic analysis was adopted to analyse data from the semi-structured interviews (Fereday $\&$ Muir-Cochrane, 2006). This hybrid approach for qualitative data analysis allows an integrated use of both deductive and inductive analysis approaches. Hence, the 'backward-and-forward' hybrid approach of thematic analysis enabled complementary data analysis and prevented the researchers from missing important data. The process of coding and categorizing were conducted manually by hand (using paper and pen strategy). Table 3 lists the following examples of the coding and categorising processes:

Table 3

Examples of the Coding and Categorising Processes

\begin{tabular}{|c|c|c|c|}
\hline Theme & Subtheme & Code & $\begin{array}{l}\text { Examples of interview } \\
\text { extracts used for coding }\end{array}$ \\
\hline \multirow[t]{2}{*}{$\begin{array}{l}\text { A curriculum } \\
\text { which inhibits/ } \\
\text { facilitates SDL }\end{array}$} & $\begin{array}{l}\text { Content of } \\
\text { curriculum }\end{array}$ & $\begin{array}{l}\text { - } \text { Flexible curriculum } \\
\text { - Crammed } \\
\text { curriculum } \\
\text { - Overloaded } \\
\text { curriculum }\end{array}$ & $\begin{array}{l}\text { "...the curriculum to be } \\
\text { flexible enough..." } \\
\text { "...the curriculum should not } \\
\text { be crammed [full] with many } \\
\text { subjects..." } \\
\text { "...the curriculum is } \\
\text { overloaded with subjects to } \\
\text { be learned..." } \\
\text { "...credit hours per semester } \\
\text { to high..." }\end{array}$ \\
\hline & $\begin{array}{l}\text { Ways of } \\
\text { teaching } \\
\text { and learning }\end{array}$ & $\begin{array}{l}\text { - Teaching straight- } \\
\text { forward } \\
\text { - Passive teaching } \\
\text { - Learn topic to be } \\
\text { tested } \\
\text { - Less active learning }\end{array}$ & $\begin{array}{l}\text { "...forces teachers to use a } \\
\text { straight-forward teaching } \\
\text { mode..." } \\
\text { "...passive teaching } \\
\text { approaches used by } \\
\text { lecturers...not support } \\
\text { SDL..." } \\
\text { “...passive method... } \\
\text { not conducive to promote } \\
\text { SDL..." } \\
\text { “...lack of guidance and } \\
\text { support..." } \\
\text { “...group activity was } \\
\text { seldom used...I like that way } \\
\text { of learning..." } \\
\text { “...focus on topic to be } \\
\text { tested and memorized..." }\end{array}$ \\
\hline
\end{tabular}




\section{FINDINGS}

Table 4 summarises the key themes and subthemes that were identified from the analysis of the data. The themes are as follows: 1) SDL as freedom in learning, 2) SDL as being in control, and 3) A curriculum which inhibits/facilitates SDL. The themes and subthemes serve to answer the main research question of 'How do university students in Malaysia conceptualise SDL?'

Table 4

Emerging Findings based on Analysis of the Qualitative Data

\begin{tabular}{ll}
\hline Theme & Subtheme \\
\hline SDL as freedom in learning & - Taking responsibility \\
& - Having choices \\
SDL as being in control & - Sharing power \\
A curriculum which inhibits / & - Content of the curriculum \\
facilitates & - Ways of teaching and learning \\
\hline
\end{tabular}

\section{Theme 1: SDL as freedom in learning; and Theme 2: SDL as being in control}

Both the themes, 'SDL as freedom in learning' and 'SDL as being in control', are discussed concurrently in this section. Based on the analysis of the interview data, it was concluded that both themes are interrelated, whereby a shift in one theme may directly influence a change in the other. As the importance of SDL to support lifelong learning are highlighted, most research participants viewed SDL as a type of learning approach that emphasises the importance of freedom in learning as it allowed them (the students) to make decisions that best suited their learning needs and interests. However, one research participants (RPA) stated that she had never experienced total freedom in learning, especially within a formal education institution. She claimed that the prescribed curriculum practised in formal educational institutions act to impose learning by determining the mandatory or required linear learning process that should be experienced by all students, even when the learning process itself has not started.

Furthermore, another research participant (RPN) stated in her extract below, that the SDL approaches were not only about having the 
freedom to decide on how to direct the learning process, but most importantly, the SDL approaches allow individuals to not adhere to other people's (teachers) expectations, and to focus on their own goals (Hiemstra, 2011).

\begin{abstract}
"To me...self-directed learning is very good not only because it promotes freedom, but I and my friends who were asked to direct their learning were given the privilege to set our own learning goals...you know... we are not being trapped to satisfy or to meet anybody's expectation." (N167-N171)
\end{abstract}

Moreover, research participant (RPB) asserted that the SDL approach is a perfect tool that makes learning interesting. Additionally, she agreed that mastering SDL skills is necessary for graduates to be successful in the future. In her own words:
“...that is why I believed self-directed learning is geared to make learning more interesting. But the bigger picture is to prepare me for the real world. So that means when I go out, I will be motivated and self-driven to self- upgrade myself ..." (B496-B499)

Furthermore, most of the research participants emphasised the ideal situation to promote SDL, where students assume responsibility for their own learning while sharing control of the learning process with educators - an idea that has received less attention in SDL literature. As supported by student participant (RPB), students' empowerment, shared control and power in learning and teaching process between students and educators, students' responsibility for successful learning, and acknowledgement of students as equal learning partners are the prerequisite components for successful self-direction that can be achieved if students were granted a certain degree of freedom and flexibility:

"I think, if educators want to include the students as active and equally important learning partners, they must be flexible with their teaching approaches...they must offer various learning alternatives for the students to choose from. This classroom environment is only 
achievable if educators and the students are willing to recognize each other's' important role in learning and teaching processes by sharing the power and control. Then, when the students choose, it shows that the educators are actually empowering the learners to take control and responsibility for their learning." (B210 B225)

This supports the initial assumption on the interconnectedness between the themes of 'Freedom' and 'Being in control'.

The description of self-directed learners portrayed by student participant (RPN) as someone who realises and appreciates his or her responsibility towards themselves, matched the characteristics of a self-directed learner propounded by many researchers (e.g. Morrison \& Navarro, 2014). She further suggested that if one wishes to become a self-directed learner, then the awareness of the responsibility to make decisions on learning should come from within. In her own words:

"So for me, self-awareness, learning goal or learning objective, self-directed learning skills and evaluation should proceed concurrently when one pursues his selfdirected learning journey. So, I believe that the previous mentioned criteria is reciprocal to each other. Having said this... if the person chooses to use a self-directed learning approach or activity, he or she must know that he is responsible for his own learning and he must be able to self-evaluate to be aware about the available learning resources that he can use to support his learning journey... at the beginning of the self-directed learning activity the person should have his own self-awareness. For instance, I am weak in English, I am aware of my weaknesses. So I aim to improve my English. I search for skills needed to help me learn English and at the end, I will evaluate my learning process. So, I divided learning into two, others-directed and self-directed." (N157-N184)

With regards to the idea of responsibility for the learning process between educators and learners, the research participants believed 
that educators who encourage SDL should provide choices for their students when deciding on their learning preferences. In the following extract, student participant (RPB) agreed that the choices in learning preferences would encourage not only freedom and flexibility, but create shared responsibility and ownership of the learning process between learners and educators.

"Because, you know... by simply giving freedom, this does not guarantee that the students will be able to proceed effectively with the learning. That is why we have lecturers... to guide the learners, not leaving them alone to solve problems. I think... with choices, teachers are actually encouraging their students to decide what is best for them... by choosing what they want to do, the responsibility of learning is transferred to the students and they can be regarded as co-partners in learning. When this happens, I believe they will take pride in the learning outcome." (B441-B450)

The collaborative partnership suggested by most research participants are supported by the findings from Grow $(1991,1994)$. The educators must play a significant role as facilitators to foster students' selfdirected learning skills.

Furthermore, more than half of the research participants had agreed that both learners and educators are responsible for ensuring successful learning. According to the research participants, although educators are responsible to tailor their pedagogical approaches to meet various learners' needs, the learners themselves should also play their respective roles effectively. The research participants emphasised that learners must have the initiative and self-motivation to learn, as proposed by Deci and Ryan (2012) in their selfdetermination theory.

"To me, learning is more on the students' part, the teacher is there to actually facilitate... just to facilitate, meaning that the teacher is just the map, the student is the driver. So the student has to take the helm, the teacher is just to guide the students to go the correct way, that's all. The initiative to learn has to come from the learners themselves." (G174-G188) 
Research participant (RPG) suggested that the ability to be in control and take charge of their own learning is crucial for self-directed learners. As students take control of their own learning process, educators and peers will not be able to impose or dictate anything on their learning process purposely. Therefore, being in control of ones' leaning process is an important element that distinguishes otherdirected learning styles from SDL. The notion of students' control in self-directed learning is closely in line with the perspectives of many researchers (Loyens et al., 2008; Jossberger et al., 2010). Furthermore, when they (the students) are in control of their own learning, they are much aware and better positioned to decide on what they want to learn, when to learn, what is the appropriate learning pace, who to consult and how to learn correctly.

\begin{abstract}
"Actually, I have taken some autonomous learning courses. So, I think, self-directed learning is all about the students taking control of their learning, for example by deciding what they want to learn. Most importantly, I believe in self-directed learning, the students take control of their learning process by deciding or devising their own learning objectives, choosing their own learning strategies, and choose their own learning material and resources. I think that is self-directed learning. The important thing is, the students are in control of their learning and nobody is forcing them to do anything that they are not willing to." (G217-G228)
\end{abstract}

\title{
Theme 3: A curriculum which inhibits/ facilitates SDL
}

This section presents the 'A curriculum which inhibits/facilitates $S D L$ ' theme that comprises of two subthemes: 'Content of the curriculum' and 'Ways of teaching'.

\section{Subtheme 1: Content of the curriculum}

A common problem that was emphasised by all research participants was the issue of overloaded university curriculums. Chambers (1992) investigated the impact of overcrowded curriculum on the practice of learning strategies among university students and found that the majority of university students forced themselves to memorize the theory and facts, as it was the easiest and fastest way to cover the 
content of the curriculum. This problem was highlighted by most of the research participants, and indicated that this may be the cause of them being dependent learners who lack the fundamental learning skills in SDL.

In relation to the issue of overloaded university curriculum, research participant (RPK) believed that the immense course content that needs to be learnt have forced students to memorise just enough to pass the course. As a consequence, the massive university curriculum content that needs to be learnt could potentially inhibit SDL.

"To me, the key to implementing self-directed learning is for the curriculum to be flexible enough to allow the teachers to creatively design their teaching. The curriculum should not be crammed [full] with many subjects, because this forces teachers to use a straight-forward lecturing mode with passive students memorising what has been taught. This passive method of learning is not conducive in promoting self-directed learning." (K357-K364).

Moreover, student participant (RPK) further asserts that due to the dense curriculum content, learning time is spent more on memorizing the content, thereby reducing the time available for students to practise their skills in SDL. As a result, the students may not experience meaningful and positive learning experiences, and are most likely wasting their efforts on superficial learning.

"One unforgettable, if not unbearable, learning experience was when my friend and I were informed that the course we were registered for used SDL approach. Without explaining exactly what SDL and problembased learning were, we were required to complete a group task. I quite often heard from my classmates about their frustrations and struggles in adapting to this new way of learning. Ultimately, the struggle to learn SDL combined with lack of guidance and feedback from the lecturer led to resistance from our group towards the implementation of SDL. All of us focused on which topic to be tested and memorized all the facts that were essential to pass this course." (K200-K237) 


\section{Subtheme 2: Ways of teaching and learning}

To tackle the issue of an overloaded curriculum, most research participants suggested that educators should innovatively and creatively design their pedagogical approaches by taking into account active learning to create meaningful learning experiences that could promote SDL. In addition, research participant (RPJ) recommended that educators should consider the curriculum content, and the teaching and learning process as complementary rather than one dominating or controlling over the other. Moreover, he suggested that teaching learning strategies (i.e. 'how' to learn) could encourage the development of students' SDL skills that would prepare them for independent learning.

"I think, our schooling experience where we are used with being spoon-fed makes us uncomfortable to learn independently. If lecturers aim to foster SDL skills among students successfully, I think it takes extra time and effort because students should be given the opportunity to experience SDL with a little bit of guidance" (J100-121)

This is further supported by Grow's SSDL model (1994) that recommends educators to match their teaching strategies with learners' readiness for self-direction. This supportive ecosystem could potentially encourage students to venture from their preferred and comfortable learning styles towards higher levels of self-directed learning.

\section{DISCUSSION AND CONCLUSION}

Upon critical review and analysis on the research participants' views and experiences of SDL, the majority of research participants have suggested that learners should be granted greater autonomy to be responsible and take control of their learning. However, the implementation of SDL learning presents challenges when incorporated into a formal and structured learning environment, where the educators' role is important for various reasons. Hence, this study proposes a balanced relationship of interconnectedness between students and educators to be established. Essentially, this 
will create a conducive learning environment in the education institutions.

The findings from this study suggest that the ideal ecosystem should be established where the curriculum content is not dense and compact. Moreover, the teaching methods should be focused on the development of self-direction skills, and not on memorising the learning contents. Students will be able to achieve learning independence and develop the necessary skills to handle the challenging working environment in the future. Therefore, based on the analysis of the interview transcripts, it is important to effectively implement SDL processes into an ideal curriculum that recognises and acknowledges the mutual interdependent relationship between students and educators.

Based on the findings by Razawi et al. (2011) on the relative dominance of learning experiences in Malaysian schools that focus on teachercentred approaches that has produced dependent learners who have struggled to cope in an independent higher learning environment, most research participants have agreed that SDL skill can be taught, and suggested that learners will become proficient in directing their learning if they were given the opportunities to practise their SDL skills in a safe and supportive learning environment. It is important to note that the development of SDL skills begin when the learner has decided to take control of his or her learning. The findings also suggest that by simply recognising the learners as active agents of learning, educators are already a step ahead in fostering SDL.

Based on the preceding discussion, Grow's SSDL model must be examined for its potential to assist educators when devising supportive learning environments that could foster the development of SDL skills among students. Furthermore, Grows' SSDL model is an important reference for educators who deal with students who are not familiar with SDL approaches as they transition from dependent to independent learner. This must be encouraged by educators to avoid any negative judgements toward new learning approaches implemented in the higher education level.

While the current understanding of SDL has been significantly shaped by existing SDL models and previous literature on SDL, this study recognises learners as key agents of SDL, the importance of learner control, learner's self-directed inclination towards his or 
her learning, and educators' role in supporting the learners' learning process.

The findings in this study reaffirm the views from current literature, and concludes that the current pedagogical practices from learners' perspective have failed to recognise the learners themselves as key agents to their learning. Furthermore, the literature reviewed indicates that educators who are inclined to foster the development of SDL among their students have often questioned the ideal characteristics of the SDL curriculum and the required skills that enable learners to function effectively within the SDL context. Therefore, to support the development of SDL within the classrooms of higher education institutions, further research needs to be conducted on the methods and approaches that can be incorporated by educators to develop learners' capacity to judge and take control of their own learning.

\section{ACKNOWLEDGEMENT}

This study was supported by FPEND Research Grant (GG-2019039) and Young Researcher Grant (GGPM-2017-076).

\section{REFERENCES}

Abu-Asba, A., Azman, H., \& Mustaffa, R. (2014). A match or mismatch between learning and teaching styles in Science education. International Journal of Education and Research, 2(3), 1-14

Akbarzadeh, M., \& Fatemipour, H. (2014). Examining the match or mismatch between teaching style preferences and upperintermediateEFLlearners'learningstylepreferences. ProcediaSocial and Behavioral Sciences, 98, 137-142.

Brockett, R. G., \& Hiemstra, R. (1991) Self-direction in adult learning: Perspectives on theory, research, and practice. London, UK: Routledge.

Candy, P. C. (1991). Self-direction for lifelong learning: A comprehensive guide to theory and practice. San Francisco, CA: Jossey-Bass.

Carré, P., Moisan, A., \& Poisson, D. (eds.). (2010). L'autoformation: Perspectives de recherche. Paris, France: Presses Universitaires de France. 
Cohen, N., \&Arieli, T. (2011). Field research in conflict environments: Methodological challenges and snowball sampling. Journal of Peace Research. 48(4), 423-435.

Cosnefroy, L., \& Carré, P. (2014). Self-regulated and Selfdirected learning: Why don't some neighbors communicate. International Journal of Self-Directed Learning. 11(2),1-12.

Deci, E. L., \& Ryan, R. M. (2012). Motivation, personality, and development within embedded social contexts: An overview of self-determination theory. In R. M. Ryan (ed.) Oxford handbook of human motivation (pp. 85-107). Oxford, UK: Oxford University Press.

Deterding, N. M., \& Waters, M. C. (2018). Flexible coding of in-depth interviews: A twenty-first-century approach. Sociological methods \& research, 0049124118799377.

Doody, O., \& Noonan, M. (2013) Preparing and conducting interviews to collect data. Nurse Researcher, 20(5), 28-32.

Douglass, C., \& Morris, S. R. (2014). Student perspectives on selfdirected learning. Journal of the Scholarship of Teaching and Learning, 14(1), 13-25.

Fereday, J., \& Muir-Cochrane, E. (2006). Demonstrating rigor using thematic analysis: A hybrid approach of inductive and deductive coding and theme development. International Journal of Qualitative Methods, 5(1), 1-11.

Flint, N. R., \& Johnson, B. (2011). Towards fairer university assessment: Recognizing the concerns of students. New York: Routledge.

Froiland, J. M., \& Worrell, F. C. (2016). Intrinsic motivation, learning goals, engagement, and achievement in a diverse high school. Psychology in the Schools, 53(3), 321-336.

Geng, S., Law, K. M., \& Niu, B. (2019). Investigating self-directed learning and technology readiness in blending learning environment. International Journal of Educational Technology in Higher Education, 16(1), 17.

Gentles, S. J., Charles, C., Ploeg, J., \& McKibbon, K. (2015). Sampling in qualitative research: Insights from an overview of the methods literature. The Qualitative Report, 20(11), 1772-1789.

Gibbons, M. (2002). The self-directed learning handbook: Challenging adolescent students to excel. San Francisco, CA: Jossey-Bass.

Griffiths, C. (ed.) (2008). Lessons from good language learners. Cambridge, UK: Cambridge University Press. 
Grow, G. O. (1991). Teaching learners to be self-directed. Adult Education Quarterly, 41(3), 125-149.

Grow, G. O. (1994). In defense of the staged self-directed learning model. Adult Education Quarterly, 44(2), 109-114.

Guglielmino, L. M. (2013). The case for promoting self-directed learning in formal educational institutions. South African Education Journal, 10(2), 1-18.

Herman, G. L. (2012). Designing contributing student pedagogies to promote students' intrinsic motivation to learn. Computer Science Education, 22(4), 369-388.

Holstein, J. A., \& Gubrium, J. F. (2008). Constructionist impulses in ethnographic fieldwork. In J. A. Holstein., \& J. F. Gubrium (eds.) Handbook of constructionist research (pp. 373-396). New York: Guilford.

Jossberger, H., Brand-Gruwel, S., Boshuizen, H., \& Wiel, M. (2010). The challenge of self-directed and self-regulated learning in vocational education: A theoretical analysis and synthesis of requirements. Journal of Vocational Education and Training, 62(4), 415-440.

Karlsson, L., Kjisik, F., \& Nordlund, J. (2007). Language counselling: A critical and integral component in promoting an autonomous community of learning. System, 35(1), 46-65.

Kidane, H. H., Roebertsen, H., \& van der Vleuten, C. P. (2020). Students' perceptions towards self-directed learning in Ethiopian medical schools with new innovative curriculum: A mixed-method study. BMC Medical Education, 20(1), 1-10.

Kovalenko, N. A., \& Smirnova, A. Y. (2015). Self-directed learning through creative activity of students. Procedia-Social and Behavioral Sciences, 166, 393-398.

Levitt-Jones,T. L., (2005). Self-directed learning: Implications and limitations for undergraduate nursing education. Nurse Education Today, 25, 363-368.

Loyens, S. M., Magda, J., \& Rikers, R. P. (2008). Self-directed learning in problem-based learning and its relationships with self-regulated learning. Educational Psychology Review, 20(4), 411-427.

Merriam, S., Caffarella, R., \& Baumgartner, L. (2007). Learning in adulthood: A comprehensive guide. $3^{\text {rd }}$ ed. San Francisco: Jossey-Bass.

Morrison, B. R., \& Navarro, D. (2014). The autonomy approach. Peaslake: Delta Publishing. Pathak, A. \& Intratat, C. (2012). 
Use of semi-structured interviews to investigate teacher perceptions of student collaboration. Malaysian Journal of ELT Research, 8(1), 1-10.

Pink, D. H. (2011). Drive: The surprising truth about what motivates us. New York: Riverhead Trade.

Razawi, N. A., Muslim, A., Che Razali, S. M., Husin, N., \& Abdul Samad, N. Z. (2011). Students' diverse learning styles in learning English as a second language. International Journal of Business and Social Science, 2(19), 179186.

Romero, D., Kwan, A., \& Suchman, L. (2019). Methodologic approach to sampling and field-based data collection for a large-scale in-depth interview study: The Social Position and Family Formation (SPAFF) project. PloS one, 14(1), 0210776.

Sadler, D. R. (2010). Beyond feedback: Developing student capability in complex appraisal. Assessment and Evaluation in Higher Education, 35(5), 535-550.

Sirat, M., Ahmad, A. R., \& Azman, N. (2012) University leadership in crisis: The need for effective leadership positioning in Malaysia. Higher Education Policy. 25(4). p.511-529.

Song, L., \& Hill, J. R. (2007). A conceptual model for understanding self-directed learning in online environments. Journal of Interactive Online Learning, 6(1), 27-42.

Sze-Yeng, F., \& Raja Hussain, R. M. (2013). Facilitating the development of self-directed learning through the design of an e-socioconstructivist learning environment (eSCLE). Current Research in Malaysia, 2(1), 139-161.

Tekkol, İ. A., \& Demirel, M. (2018). An investigation of selfdirected learning skills of undergraduate students. Frontiers in psychology, 9, 2324

Thornton, K. (2010). Supporting SDL: A framework for teachers. Language Education in Asia. 1(1), 158-170.

Trigwell, K., \& Prosser, M. (1991). Improving the quality of student learning: The influence of learning context and student approaches to learning on learning outcomes. Higher Education, 22(3), 251-266.

Van Woezik, T., Reuzel, R., \& Koksma, J. (2019). Exploring Open Space: A self-directed learning approach for higher education. Cogent Education, 6(1), 1615766.

Weimer, M. (2002). Learner-centered teaching: Five key changes to practice. San Francisco: Jossey-Bass. 
Yeoh, M. P., Cazan, A. M., Ierardi, E., \& Jacić, L. A. (2017). Facilitating self-directed learning (SDL) and satisfaction with SDL among pre-university students. Educational Studies, 43(5), 584-599. 